\title{
LCOE Analysis of Solar Tracker Application in China
}

\author{
Qingcai Liu, Xuechun Wan \\ Guangzhou Railway Polytechnic, Guangzhou, China \\ Email: 807431278@qq.com
}

How to cite this paper: Liu, Q.C. and Wan, X.C. (2020) LCOE Analysis of Solar Tracker Application in China. Computational Water, Energy, and Environmental Engineering, 9, 87-100.

https://doi.org/10.4236/cweee.2020.94007

Received: July 4, 2020

Accepted: August 14, 2020

Published: August 17, 2020

Copyright $\odot 2020$ by author(s) and Scientific Research Publishing Inc. This work is licensed under the Creative Commons Attribution International License (CC BY 4.0).

http://creativecommons.org/licenses/by/4.0/

(c) (i) Open Access

\begin{abstract}
In China, systemic techno-economic analysis for solar tracker has been absent. To fill the blank, by taking the economic analysis of solar tracker application as the research object and using the LCOE method widely used internationally, the techno-economic analysis model of solar tracker was established according to conditions in China. Influence factors on LCOE were analyzed by using the established model, and the relationship between each cost factor and the cost component of energy leveling of tracker was further studied. In addition, the calculation method of investment payback period based on energy leveling analysis was established, and the influence of various factors on investment payback period was revealed through an example calculation. The research results will help to measure the economy of tracker application more accurately and comprehensively, and promote the popularization and application of solar tracker. The economic analysis model of solar tracker application was established by using LCOE method. The influence factors and cost component of LCOE were analyzed with the model. The payback period of solar tracker investment was also analyzed based on LCOE method.
\end{abstract}

\section{Keywords}

Solar Energy, PV Power Generation, Solar Tracker, LCOE, Techno-Economic Analysis

\section{Introduction}

PV generation can increase the power generation of photovoltaic system by using tracker, but with capital investment, the cost increases. Whether to use tracker or not, it is necessary to estimate the cost-effectiveness ratio to ensure that a project implementation can bring positive benefits. 
At present, energy leveling method, also known as LCOE (Levelized cost of energy), is widely used to calculate energy costs. The method of LCOE takes into account all the costs incurred in the life cycle of a power generation system, including equipment procurement, installation and commissioning, operation and maintenance, loan financing, equipment depreciation, land cost, interest rates and inflation, as well as all the energy output produced in the life cycle. When calculating, the cost and value of all the time points are converted to the present value of the starting time.

In order to promote the development of photovoltaic power, the National Renewable Energy Laboratory of the United States has developed SAM software to calculate the cost of photovoltaic power plants by LCOE evaluation [1]. Warren Nishikawa and other researchers used LCOE method to evaluate the economy of concentrating photovoltaic. The results show that the use of concentrating photovoltaic is competitive under the conditions of strong solar radiation, limited land area and high ambient temperature when the price of photovoltaic power is high [2]. Daniel G. Wright et al. put forward a method combining fuzzy mathematics to evaluate the cost of renewable energy projects [3]. M. S. Adaramola et al. studied the cost of small and medium-sized wind turbines in six different locations in north-central Nigeria by using the LCOE method, and identified the most suitable locations for wind power development. The study also revealed that changes in operation and maintenance costs and inflation rates have a significant impact on power generation costs and investment returns [4]. Richard A. Whisnant et al. systematically studied the economic analysis method of photovoltaic power. Based on the present and future values of photovoltaic power projects, a method for calculating LCOE was proposed [5]. Mevin Chandal et al. studied the design of a photovoltaic power generation project for a garment industrial zone in Jaipur, India. In the scheme, the LCOE method was used to calculate the electricity price of the power station located in the industrial zone and far away from the industrial zone [6]. Kh. S. Karimov et al. designed a small simple tracking system, which consists of three brackets, one of which is used as the rotating shaft, and the other two brackets are adjustable in length. The track was installed at a solar irradiance of $800 \mathrm{~W} / \mathrm{m}^{2}$ (AM 1.5 spectral distribution), and at temperature of $25^{\circ} \mathrm{C}$. The system cost is analyzed and its cost is equivalent to that of diesel engine power generation. It is suitable for household use or similar cathodic protection in rural and remote areas [7].

In terms of solar tracker application, J. Vermaak studied the economy of using solar trackers in South Africa. By comparing with the power generation data of fixed assembly running for one year, the single-axis and double-axis tracker can increase the power generation by $33 \%$ and $37 \%$ respectively in $1 \mathrm{KW}$ system. However, due to the shadow problem caused by tracker, the area occupied by tracker is enlarged, and the power generation per unit area is only $15.44 \%$ and 22.28\% of the fixed installation [8]. I. M. Michaelides compared the performance and cost-effectiveness ratio of three different types of water heaters in Athens, Greece, and Nicosia, Cyprus. The results show that the performance of the col- 
lector is the highest. The second is seasonal tracking, and the worst is fixed installation. However, fixed installation is the best cost-effectiveness ratio, and the payback period of uniaxial tracker and seasonal tracking is significantly prolonged [9]. George Cristian Lazaroiu et al. compared the daily energy output performance of fixed and tracking small photovoltaic systems. It was found that the power output of the photovoltaic system with single-axis tracker increased significantly in the morning and afternoon compared with that of the fixed installation system under the condition of considering the tracker energy consumption [10].

Many scholars have done a lot of research on solar trackers. These studies mainly focused on the design, performance, feasibility or technical and economic analysis of various solar trackers. There is no systematic technical and economic analysis of solar trackers using LCOE method. Regarding the solar tracker as an energy system, with the LCOE method widely used in the world, the paper took the economic analysis of the application of solar tracker as research object and tried to perform its cost-benefit analysis. Investment on solar trackers may not necessarily increase accumulated gain from a PV plant. It was hoped that the research results would be helpful to measure the economy of solar trackers more accurately and comprehensively, and promote the popularization and application of solar trackers.

\section{Model of LCOE Calculation}

The present study is concerned with solar trackers' techno-economic analysis in China with LCOE method. In order to make evaluation conform to conditions in China, many specific factors were considered, including electricity price, investment per watt for tracker, loan and period, interest rate and inflation rate, annual operating and maintenance cost, depreciation and period, salvage, value added tax and additional tax, income tax, land cost, output increase factor with tracker, annual power output from static PV panel, conversion efficiency attenuation rate. The following calculation for the LCOE is the net present value of total life cycle costs of a project divided by the quantity of energy produced over the tracking system life [11]:

$$
\begin{aligned}
\text { LCOE } & =\frac{\text { total life cycle cost }}{\text { total life energy production }} \\
& =\frac{I(1-\eta)+\text { O\&M }+T+B+C-D-S}{E}
\end{aligned}
$$

In Formula (1). Where, all parameters meanings can be seen in nomenclature. The specific expressions are as follows:

$$
\begin{gathered}
\mathrm{O} \& \mathrm{M}=\sum_{n=1}^{L} \frac{\varepsilon I}{(1+r)^{n}} \\
C=\sum_{n=1}^{N_{B}} \frac{I \eta i\left(1-\frac{n-1}{N_{B}}\right)}{(1+r)^{n}}
\end{gathered}
$$




$$
\begin{gathered}
D=\sum_{n=1}^{N_{D}} \frac{I}{N_{D}(1+r)^{n}} \\
S=\frac{I \gamma}{(1+r)^{L}} \\
E=\sum_{n=1}^{L} \frac{\alpha W_{1}\left(1-i_{w}\right)^{n-1}}{(1+r)^{n}} \\
B=\sum_{n=1}^{N_{B}} \frac{I \eta}{N_{B}(1+r)^{n}} \\
T=T_{v a}+T_{i n}+T_{L} \\
T_{v a}=\sum_{n=1}^{L} \frac{\alpha W_{1} P_{w}\left(1-i_{w}\right)^{n-1} i_{\text {Tva }}}{(1+r)^{n}} \\
T_{L}=\sum_{n=1}^{L} \frac{P_{L} S_{L} \beta}{(1+r)^{n}}
\end{gathered}
$$

where, all parameters meanings can be seen in nomenclature.

According to the literature [4],

$$
\begin{gathered}
r=\frac{1+i}{1+e_{a}}-1 \\
T_{i n}=\left[\sum_{n=1}^{L} \frac{\alpha W_{1} P_{w}\left(1-i_{w}\right)^{n-1}}{(1+r)^{n}}-\mathrm{O} \& \mathrm{M}-C-D-T_{v a}-T_{L}\right] i_{i n c}
\end{gathered}
$$

When calculating Formula (12), Formulas (2)-(4), (8)-(11) are introduced into Formula (12).

\section{Analysis of Main Influencing Factors of Tracker LCOE}

Before you begin to format your paper, first write and save the content as a separate text file. Keep your text and graphic files separate until after the text has been formatted and styled. Do not use hard tabs, and limit use of hard returns to only one return at the end of a paragraph. Do not add any kind of pagination anywhere in the paper. Do not number text heads-the template will do that for you.

The model described above seems very complex and involves so many parameters. In order to discuss the extent of parameters' impact on LCOE, a set of typical parameters were used to show exact relationships between LCOE value and parameters. All selected parameters are based on conditions in China, such as price regulated by government, tax reduction or exemption, solar resource, land cost, attainable technical level. Except those stated in diagrams, parameter values are shown in Table 1. A group of curves are shown from Figure 1 to Figure 2.

In Figure 1 and Figure 2, vertical axis represents LCOE, horizontal axis has different meanings for different curves. Meanings for curves were shown in 


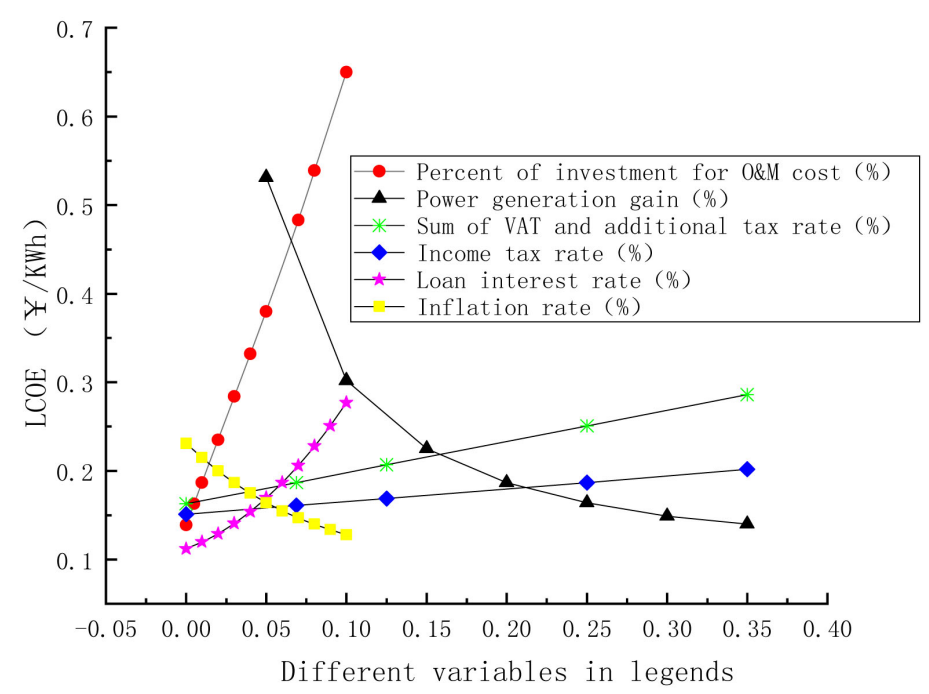

Figure 1. Relationship 1 between solar tracker's LCOE and impact factors.

Table 1. Parameters used in calculation.

\begin{tabular}{|c|c|}
\hline Parameters symbol & values \\
\hline$P_{w}$ & $0.4 ¥ /(\mathrm{kWh})$ \\
\hline$P_{L}$ & $1 ¥ /\left(\mathrm{m}^{2} \mathrm{a}\right)$ \\
\hline$S_{L}$ & $0.01 \mathrm{~m}^{2} / \mathrm{W}$ \\
\hline$\beta$ & $30 \%$ \\
\hline$i$ & $6 \%$ \\
\hline$e_{a}$ & $3 \%$ \\
\hline$I$ & $1.5 ¥ / \mathrm{W}$ \\
\hline$\varepsilon$ & $1 \%$ \\
\hline$W_{1}$ & $1.5 \mathrm{kWh} / \mathrm{a}$ \\
\hline$i_{w}$ & $1 \%$ \\
\hline$i_{\text {Tva }}$ & $6.89 \%$ \\
\hline$i_{i n c}$ & $25 \%$ \\
\hline$\alpha$ & $20 \%$ \\
\hline$\eta$ & $70 \%$ \\
\hline$N_{B}$ & $5 \mathrm{a}$ \\
\hline$L$ & $25 \mathrm{a}$ \\
\hline$\gamma$ & 0.05 \\
\hline$N_{D}$ & $10 \mathrm{a}$ \\
\hline
\end{tabular}

Note: 1. $P_{w}$ value from government price regulation for first class PV energy area in China. $2 . W_{1}$ is based on 1500 hours guaranteed in China's first class area. 3. $i_{T r a}$ is based on government tax regulation. 4 . $i_{\text {inc }}$ is 0 for first 3 years and $12.5 \%$ for second 3 years, $25 \%$ for other time. 


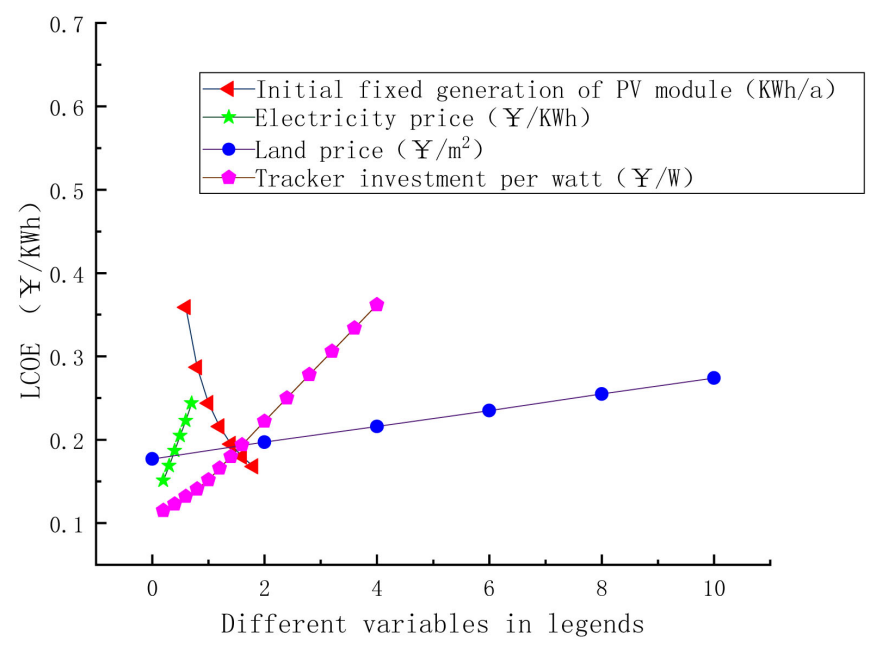

Figure 2. Relationship 2 between solar tracker's LCOE and impact factors.

diagram with different legends. Two diagrams have same scope of vertical axis. The order of horizontal coordinates for Figure 1 is smaller than that in Figure 2, so curves were drawn in 2 diagrams to avoid too congested to distinguish. When calculating a curve, the values of other parameters remain unchanged.

In Figure 1 and Figure 2, steeper curve means bigger impact on LCOE. The steepest curve is percent of investment for $\mathrm{O} \& \mathrm{M}$ cost. It is obvious to see in Figure 1 that LCOE will change sharply when there is a very small change of Percent of investment for $\mathrm{O} \& \mathrm{M}$ cost, so we can say Percent of investment for $\mathrm{O}$ \& $\mathrm{M}$ cost is the most sensitive factor affecting LCOE. O \& $\mathrm{M}$ cost includes maintenance cost and downtime loss of production. Hence to decrease LCOE, solar tracker must have very good reliability. Solar tracker with high breakdown rate will inevitably lead to loss of economic competitiveness. Lower Percent of investment for $\mathrm{O} \& \mathrm{M}$ cost requires that solar tracker not only has lower price but also has higher reliability, and this reveals the technical difficulties and development direction of tracker for photovoltaic power plants.

The power generation gain curve in Figure 1 shows that the power generation gain or percentage brought by tracker increases with tracking accuracy, and the LCOE value of tracker decreases rapidly. The power generation gain curve also shows that the LCOE value decreases slowly when the power generation gain reaches a certain value. Curve characteristics reflect that only when tracker has a certain tracker accuracy, the installation of tracker can bring positive benefits. On the other hand, it also shows the economic rationality of uniaxial tracker, that is, low cost uniaxial tracker, which is also worthwhile when the percentage of generation gain reaches a certain value. Bi-axis tracker has high accuracy and large power generation gain, but the cost will obviously increase, and the reliability will be reduced due to the complexity of system. Combining with the relationship curve of tracker investment per watt and LCOE in Figure 2, we can see that LCOE increases with unit investment. If the cost cannot be reasonably controlled at a certain level or the cost is too high, blind pursuit of two-axis tracker does not necessarily have economic competitiveness. 
Enterprise investment generally does not use its own capital completely. It will generate borrowing costs by borrowing from banks. The cost of borrowing is related to interest rates and inflation rates. As can be clearly seen from Figure 1, the LCOE value of tracker increases with the increase of interest rate and decreases with the increase of inflation rate. Therefore, it is very advantageous to seek funds with low interest rates as much as possible. When the inflation rate is high, the interest rate is appropriate. Appropriate loan financing is beneficial, which can reduce the LCOE value of tracker.

The curve of VAT and additional tax in Figure 1 shows their impact on LCOE. The income tax curve shows the impact of income tax on LCOE. By comparison we can see that the impact of income tax is less than that of VAT and additional tax. As can be seen from Figure 1, the LCOE value of tracker increases with the increase of tax rate. When the tax rate is high, it will lead to the deterioration of the economy of using trackers. Figure 1 also shows that for solar tracker applications, lower tax rate is conducive to the economic improvement of project, but also conducive to the application and promotion of related technical equipment.

The initial fixed installed power generation of photovoltaic modules reflects the photoelectric conversion performance of panels and regional solar energy resources to a certain extent. From the curve of LCOE and initial fixed power generation of the modules in Figure 2, it can be seen that the value of LCOE decreases rapidly with the increase of the power generation capacity of the panels. Installation of solar trackers is not economical if the power generation capacity of photovoltaic panels is too low. If the power generation capacity of the solar panel is high, the LCOE value can be reduced, which indicates that in a region rich in solar energy resources, it is more economical to install solar trackers with high performance solar panels.

Figure 2 also illustrates the relationship between the LCOE value of tracker and the direct investment cost allocated to tracker per watt. The LCOE value of tracker increases rapidly with the increase of unit cost per watt. But when the cost of tracker is reduced to zero, the LCOE value of tracker is not zero. The reason for this phenomenon is that the LCOE value of tracker is related not only to the investment cost of tracker, but also to the maintenance cost, tax cost and land cost. The cost curve in Figure 2 shows that reducing the cost of tracker is the most direct and effective way to ensure the economy of tracker while ensuring its reliability. In order to reduce the cost per watt of tracker, a new structure design can be used to reduce the cost. It can also consider increasing the component load of a single tracker to reduce the cost. Given the electricity price given in this paper, the cost per watt of some tracker products on the market has reached $8-10 ¥$, which is not economical.

The land price curve in Figure 2 shows that land price also has an impact on the economy of tracker. When land price rises, the LCOE value of tracker rises. If land price reaches a certain level, the LCOE value may exceed the electricity price. At this time, the profit of tracker is negative, which is not worth the loss. 
From another point of view, it also shows that if the land is desert or idle land that can't be used, the price is lower, the economy of using tracker is better.

As can be seen from Figure 2, the relationship between the LCOE value of tracker and electricity price. With the rise of electricity price, LCOE value also increases. The reason is that when electricity price rises, the revenue from electricity sales increases and the related taxes and fees paid increase. However, the LCOE value growth is limited within the range where electricity price may be valued.

Under given conditions in Table 1, according to the degree of influence, the factors leading to the increase of LCOE are tracker operation and Percent of investment for $\mathrm{O} \& \mathrm{M}$ cost, direct investment per watt, loan interest rate, income tax rate, value-added tax and additional tax rate, land price and electricity price. Percent of investment for $\mathrm{O} \& \mathrm{M}$ cost is the most sensitive factor, which may determine the success or failure of a project.

Under given conditions in Table 1, according to the degree of impact, the factors leading to the decrease of LCOE of tracker are: the power generation gain after tracker is installed, the initial fixed installed power generation of the photovoltaic module, and the inflation rate.

\section{LCOE Component Analysis of Solar Tracker}

The factors affecting the LCOE of tracker were analyzed above. The factors that constitute the LCOE vary in degree. The proportion of each cost in the LCOE was shown in Figure 3. Unless otherwise given in the figure, values was given in Table 1. LCOE of solar tracker mainly includes capital cost, maintenance cost, VAT and additional tax, income tax and land cost. Among them, the capital cost is the discounted value of the total input of tracker after deducting depreciation fees and residual value.

In Figure 3, when tracker unit investment is high, the largest proportion of tracker LCOE is capital cost, or investment cost. Reducing the cost of design,

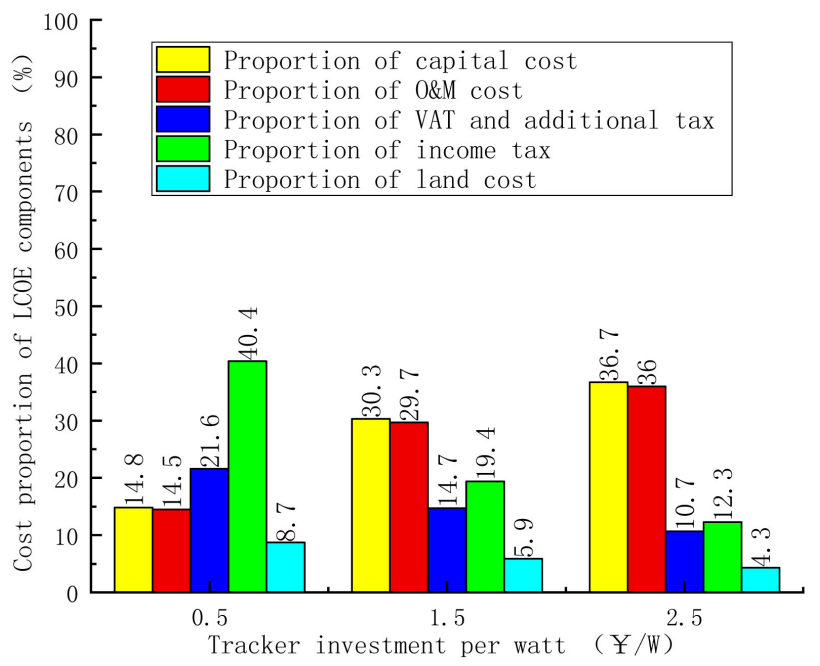

Figure 3. LCOE component at different investment per watt. 
manufacture and installation of tracker can effectively reduce the LCOE cost of tracker. This can take into account the standardization, modularization of trackers, and the general design of components, so as to reduce the cost of design, manufacturing and installation. Universal design of spare parts is also conducive to reducing maintenance costs.

Combining with Figure 3 and Figure 4, it can be seen that the maintenance cost of tracker lifetime is equal to the cost of capital under the given Percent of investment for $\mathrm{O} \& \mathrm{M}$ cost in Table 1. If the Percent of investment for $\mathrm{O} \& \mathrm{M}$ cost rises slightly, the proportion of maintenance cost will also increase. Therefore, it is very important to control the LCOE value by improving its reliability, reducing failure rate, reducing maintenance time and increasing fault interval. From field experience, it is reliability that affects the use of domestic trackers. Because of the existence of motor, reducer, control system and protection system, the structure of tracker is more complex than that of fixed battery plate, and there are moving parts, so the probability of failure increases. In addition, the coupling of tracker and photovoltaic system may cause new faults.

Figure 5 shows that the impact of VAT and additional tax on LCOE of tracker is second only to the impact of investment cost and maintenance cost of tracker. The data in the figure take into account the reduction of VAT by half. If there is no tax reduction measures, the impact will certainly increase. This also shows that in order to encourage the development of photovoltaic power, it is beneficial to adopt tax reduction or tax concessions.

The impact of the tax shown in Figure 6 on LCOE values of tracker is relatively small under the current "three years exemptions, three years halves" policy which was noted as item 3 in notes of Table 1 .

Land price, including land tax or land rent, also has an effect on the economy of tracker, but it has little effect under the condition of setting low land price. Combining with Figure 7, we can see that the impact of land cost increases rapidly with the increase of land price.

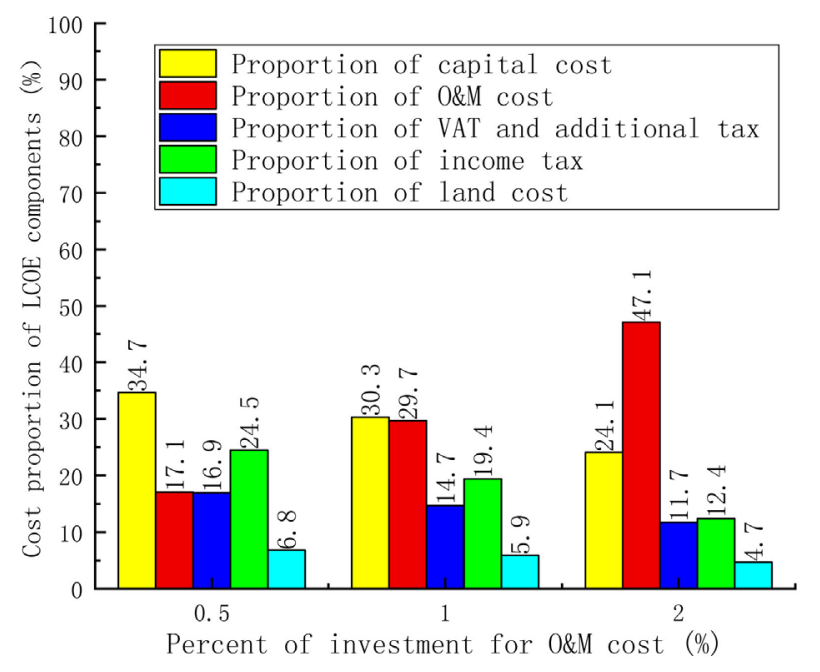

Figure 4. LCOE component at different O \& M rates. 


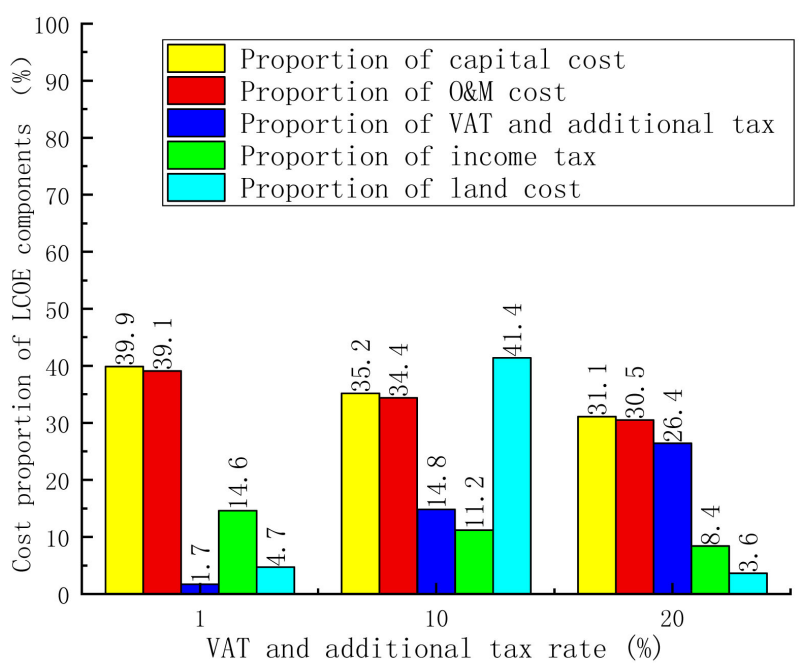

Figure 5. LCOE component at different VAT and additional tax rate.

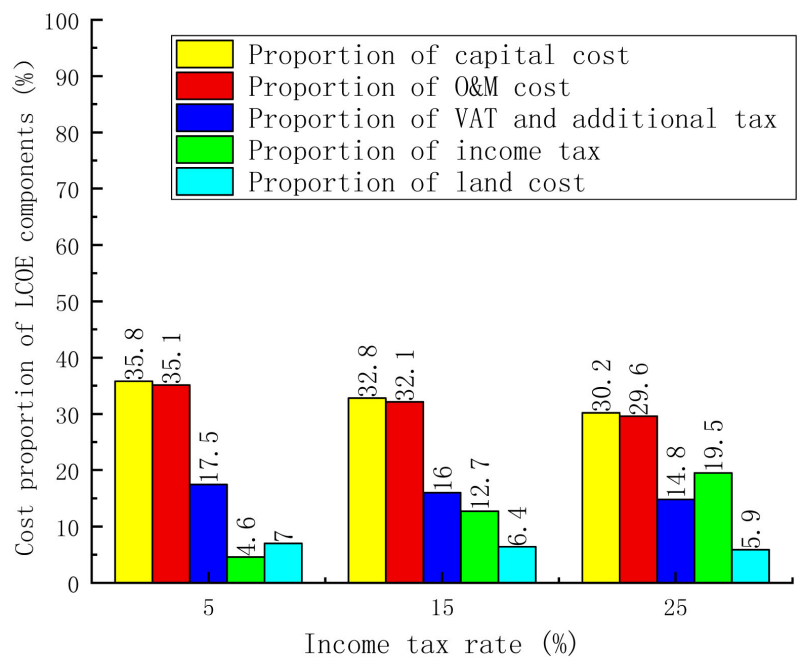

Figure 6. LCOE component at different income tax rate.

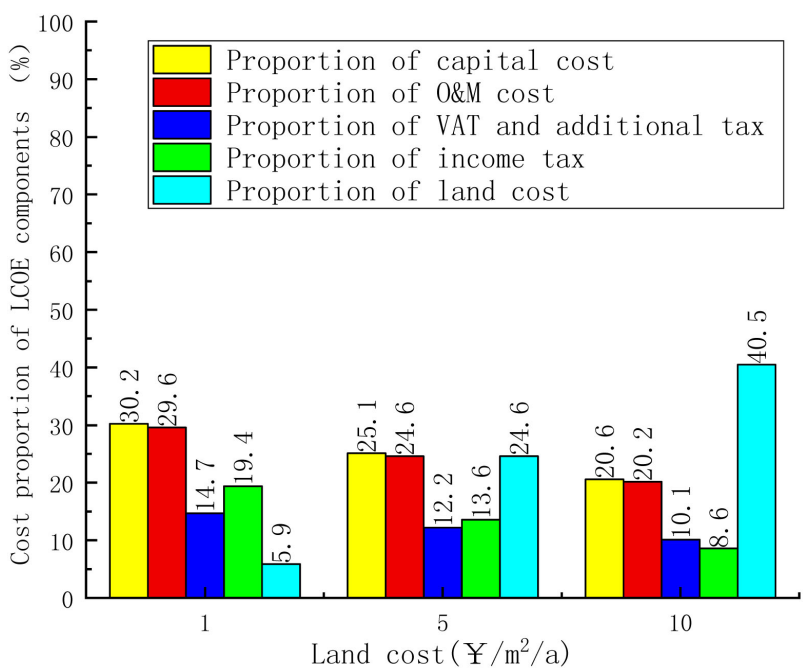

Figure 7. LCOE component at different land cost. 


\section{Calculating the Payback Period of Investment Based on LCOE}

For projects using trackers, investors are concerned about the payback period. Therefore, the LCOE-based method was used to calculate the payback period of tracker's investment cost. The method of calculating the payback period of investment is to determine how many years it will take for the sales revenue to exactly equal or exceed tracker cost in the calculation period. The payback period should satisfy the following formulas:

$$
\begin{aligned}
& \sum_{n=1}^{N_{I}} \frac{\alpha W_{1}\left(1-i_{w}\right)^{n-1} P_{w}}{(1-r)^{n}}
\end{aligned}
$$

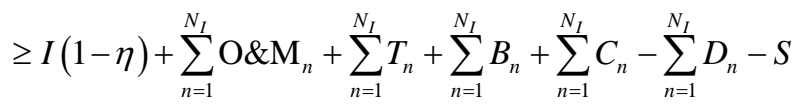

where $N_{I}$ is the payback period of investment, other symbols meaning can be seen in nomenclature. Symbol with subscript $n$ represents the present value of the nth year.

The left side of the formula represents the electricity sales revenue over a period of time. The payback period calculated by Formula (13) is shown in Table 2. Each data given in Table 2 corresponds to the data required for the calculated payback period as shown in Table 1.

Table 2. Results of payback period calculation.

\begin{tabular}{|c|c|c|}
\hline Cost item & values & Payback period/a \\
\hline & $2.5 ¥ / \mathrm{W}$ & 10 \\
\hline \multirow[t]{3}{*}{ Investment per watt } & $1.5 ¥ / \mathrm{W}$ & 8 \\
\hline & $0.5 ¥ / \mathrm{W}$ & 3 \\
\hline & $5 \%$ & 13 \\
\hline \multirow[t]{3}{*}{ Percent of investment for $O \& M$ cost } & $2.5 \%$ & 9 \\
\hline & $1 \%$ & 8 \\
\hline & $8 \%$ & 9 \\
\hline \multirow[t]{3}{*}{ Interest rate } & $5 \%$ & 7 \\
\hline & $2 \%$ & 7 \\
\hline & $6 \%$ & 7 \\
\hline \multirow[t]{3}{*}{ Inflation rate } & $3 \%$ & 8 \\
\hline & $1 \%$ & 8 \\
\hline & 0 & 7 \\
\hline \multirow[t]{3}{*}{ VAT and Additional tax } & $6.89 \%$ & 8 \\
\hline & $15 \%$ & 8 \\
\hline & 0 & 8 \\
\hline \multirow[t]{3}{*}{ Income tax } & $12.5 \%$ & 8 \\
\hline & $25 \%$ & 8 \\
\hline & $10 ¥ / \mathrm{m}^{2} / \mathrm{a}$ & 9 \\
\hline \multirow[t]{2}{*}{ Land price } & $5 ¥ / \mathrm{m}^{2} / \mathrm{a}$ & 8 \\
\hline & $1 ¥ / \mathrm{m}^{2} / \mathrm{a}$ & 8 \\
\hline
\end{tabular}


From Table 2, we can see that the payback period of tracker is the most sensitive to unit investment, and the percent of investment for $\mathrm{O} \& \mathrm{M}$ cost is also more sensitive. In the low Percent of investment for $\mathrm{O} \& \mathrm{M}$ cost stage, the impact on the investment payback period is not obvious, but when the percent of investment for $\mathrm{O} \& \mathrm{M}$ cost is higher, the payback period of the investment becomes longer quickly. This is because the payback period is not only affected by maintenance cost, but also by investment funds, tax and land cost. The influence of other factors is relatively small. Interest rate and inflation rate mainly affect the payback period by affecting the cost of investment funds. The payback period increases with the increase of interest rate. Higher inflation will shorten the payback period. Under the current tax conditions, the payback period increases slightly with the increase of value added tax and additional tax rates. The income tax rate has no obvious effect on the payback period of investment under the current policy. The cost of land rises from $1 ¥ / \mathrm{m}^{2}$ to $10 ¥ / \mathrm{m}^{2}$, and the payback period of investment is extended from 8 years to 9 years. Land cost has influence but not significant.

From the data in Table 2, it can be concluded that if solar tracker is to be used in domestic first class solar energy resource areas, tracker must be low cost and have high reliability. At the same time, we should make the best use of low-cost land and low-interest funds and get preferential tax revenue.

\section{Conclusions}

The economic analysis model of solar tracker application was established by using LCOE method. The influencing factors and cost component of LCOE were analyzed with the model. The payback period of solar tracker investment was also analyzed based on LCOE method.

The impact factors on the rising of LCOE with importance value from big to small are tracker maintenance rate, direct investment per watt, loan interest rate, income tax rate, value-added tax and additional tax rate, land price and sales price. Maintenance rate is the most sensitive factor, which may determine the success or failure of PV project.

According to the degree of impact, the factors leading to the reduction of the LCOE of tracker are: the power generation gain after the installation of tracker, the initial fixed installed power generation of photovoltaic module, and the inflation rate.

Among costs of LCOE, under given conditions, capital cost and maintenance cost account for the main part, followed by tax cost and land cost.

According to the calculation method of LCOE's investment payback period, the unit investment of tracker has the greatest impact on the investment payback period, followed by the Percent of investment for $\mathrm{O} \& \mathrm{M}$ cost of tracker, which also has a great impact on the investment payback period. Especially in the case of poor reliability of equipment, the increase of maintenance cost will greatly prolong the period of investment payback. Other cost factors have relatively small impact. 


\section{Acknowledgements}

This article was funded by the 2018 online open courses project of Guangdong Department of Education (Document No. [2018] 194 from Guangdong Department of Education).

\section{Conflicts of Interest}

The authors declare no conflicts of interest regarding the publication of this paper.

\section{References}

[1] Gilman, P. (2015) SAM Photovoltaic Model Technical Reference. https://www.nrel.gov/docs/fy15osti/64102.pdf https://doi.org/10.2172/1215213

[2] Warren, N., Steve, H. and Jane, M. (2008) LCOE for Concentrating Photovoltaics (CPV). Proceedings of International Conference on Solar Concentrators for the Generation of Electricity (ICSC-5), Palm Desert, CA, 16-19 November 2008.

[3] Daniel, G.W., Prasanta, K.D. and John, G.B. (2013) A Fuzzy Levelised Energy Cost Method for Renewable Energy Technology Assessment. Energy Policy, 62, 315-323. https://doi.org/10.1016/j.enpol.2013.07.077

[4] Adaramola, M., Paul, S. and Oyedepo, S. (2011) Assessment of Electricity Generation and Energy Cost of Wind Energy Conversion Systems in North-Central Nigeria. Energy Conversion and Management, 52, 3363-3368.

https://doi.org/10.1016/j.enconman.2011.07.007

[5] Luque, A. and Hegedus, S. (2002) Economic Analysis and Environmental Aspects of Photovoltaic Systems. In: Antonio, L. and Steven H., Eds., Handbook of Photovoltaic Science and Engineering, John Wiley \& Sons Ltd., West Sussex, England, 973-980. https://doi.org/10.1002/0470014008

[6] Mevin, C., Agrawal, M.G., Sanjay, M. and Anuj, M. (2014) Techno-Economic Analysis of Solar Photovoltaic Power Plant for Garment Zone of Jaipur City. Case Studies in Thermal Engineering, 2, 1-7. https://doi.org/10.1016/j.csite.2013.10.002

[7] Karimova, Kh.S., Saqib, M.A., Akhter, P., Ahmed, M.M., Chattha, J.A. and Yousafzai, S.A. (2005) A Simple Photo-Voltaic Tracking System. Solar Energy Materials \& Solar Cells, 87, 49-59. https://doi.org/10.1016/j.solmat.2004.08.010

[8] Vermaak, H.J. (2014) Techno-Economic Analysis of Solar Tracking Systems in SouthAfrica. Energy Procedia, 61, 2435-2438. https://doi.org/10.1016/j.egypro.2014.12.018

[9] Michaelides, I.M., Kalogirou, S.A. and Chrysis, I. (1999) Comparison of Performance and Cost Effectiveness of Solar Water Heaters at Different Collector Tracking Modes in Cyprus and Greece. Energy Conversion \& Management, 40, 1287-1303. https://doi.org/10.1016/S0196-8904(99)00020-5

[10] George, C.L., Michela, L., Mariacristina, R. and Mario, P. (2015) Comparative Analysis of Fixed and Sun Tracking Low Power PV Systems Considering Energy Consumption. Energy Conversion and Management, 92, 143-148. https://doi.org/10.1016/j.enconman.2014.12.046

[11] Campbell, M. (2008) The Drivers of the Levelized Cost of Electricity for Utility-Scale Photovoltaics.

https://us.sunpower.com/sites/sunpower/files/media-library/white-papers/wp-leveli zed-cost-drivers-electricity-utility-scale-photovoltaics.pdf 


\section{Nomenclature or Abbreviations}

$B$ : present value of loan reimbursement ( $¥ / \mathrm{W})$

$C$ : present value of loan interest Cost (¥/W)

$D$ : present value of depreciation ( $¥ / \mathrm{W}$ )

$E$ : present value of increased power output with solar tracker $(\mathrm{kWh} / \mathrm{W})$

$e_{a}$ : inflation rate (\%)

I: tracker investment per watt (¥/W)

$i_{\text {Tva }}$ : the sum of VAT rate and additional tax rate (\%)

$i_{w}$ : attenuation rate of conversion efficiency of PV panel (\%/a)

$i$ interest rate (\%)

LCOE: levelized cost of energy ( $¥ / \mathrm{kWh})$

$L$ : solar tracker's lifetime (a)

$N_{B}$ : period of loan (a)

$N_{D}$ : period of depreciation (a)

$\mathrm{O} \& \mathrm{M}$ : present value of operating and maintenance cost per watt (¥/W)

PV: photovoltaic

$P_{w}$ : the price of PV electricity ( $\left.¥ / \mathrm{kWh}\right)$

$P_{L}:$ land price $\left(¥ / \mathrm{m}^{2}\right)$

r. real discount rate $(\%)$

$S$ : present value of salvage ( $¥ / \mathrm{W})$

$S_{L}$ : land area per watt of fixed $\mathrm{PV}$ panel $\left(\mathrm{m}^{2} / \mathrm{W}\right)$

$T$ : present value of all kinds of tax per watt $(¥ / \mathrm{W})$

$T_{v a}$ : value added tax and additional tax $(¥ / \mathrm{W})$

$T_{L}$ : land cost $(¥ / \mathrm{W})$

$T_{\text {in }}$ : income tax cost $(¥ / \mathrm{W})$

VAT: value added tax

$W_{1}$ : initial fixed generation capacity of photovoltaic modules $(\mathrm{kWh} / \mathrm{a} / \mathrm{W})$

$\alpha$ : power generation gain with tracker (\%)

$\beta$ : percent of increased land for PV system with solar trackers (\%)

$\gamma:$ salvage factor (salvage fraction of total investment per watt)

$\varepsilon$ : percent of investment for $\mathrm{O} \& \mathrm{M}$ cost $(\% / \mathrm{a})$

$\eta$ : proportion of Loan in Total Investment of Each Watt 